\title{
PENGARUH ROLE STRESSOR TERHADAP TURNOVER INTENTION DENGAN JOB SATISFACTION SEBAGAI VARIABEL INTERVENING DI PERUSAHAAN BONGKAR MUAT X SURABAYA
}

\author{
Avedo Satya Mandiri \\ Fakultas Ekonomi dan Bisnis, Universitas Airlangga Surabaya \\ e-mail: avedo.mandiri@gmail.com
}

\begin{abstract}
Stress can be sourced from several factors or commonly known as stressors. Operational employee has been identified as a job that has high stress level. Hang-yue (20056) states that an employee who is under stress due to sources of stress can have an impact on decreasing job satisfaction. This can also lead to increased turnover intention. The purpose of this study was to determine the effect of role stressor on turnover intention directly nor indirectly. This study using quantitative approach and nonprobability sampling technique with saturated sampling of 40 employees from operational division's stevedoring company in Surabaya. Data analysis techniques using path analysis. The results showed that there was a significant negative effect between role stressor and turnover intention directly nor indirectly.
\end{abstract}

Keywords: job satisfaction, role stressor, turnover intention

\section{PENDAHULUAN}

Perubahan lingkungan internal dan eksternal pada suatu perusahaan perlu diantisipasi karena dapat berdampak pada produktivitas perusahaan. Salah satu perubahan lingkungan internal yang berperan adalah keluar/masuknya karyawan (turnover). Dalam suatu perusahaan, pergantian atau keluar masuknya karyawan adalah suatu fenomena penting di mana pada kalanya pergantian karyawan memiliki dampak positif. Namun sebagian besar pergantian karyawan memiliki dampak negatif bagi perusahaan, yakni dari segi peningkatan biaya sumber daya manusia berupa biaya pelatihan yang sudah dikeluarkan untuk karyawan dari biaya rekrutmen hingga pelatihan kembali dan hilangnya waktu karena perusahaan perlu melakukan kembali pelatihan kepada karyawan baru serta kesempatan memanfaatkan peluang bisnis yang ada.

Salah satu faktor yang dapat mengindikasikan karyawan akan meninggalkan suatu perusa- haan adalah niat sukarela karyawan untuk meninggalkan organisasi (Berry, 2008). Menurut Spector (2012) turnover intention merupakan pendahulu terkuat dari actual turnover. Mobley et al. (1979) juga mengemukakan pernyataan yang sama bahwa perilaku keinginan untuk keluar atau tinggal secara konsisten berhubungan dengan turnover.

Penyebab turnover intention dapat dipengaruhi oleh banyak faktor. Penelitian yang dilakukan oleh Saeed et al. (2014) menemukan bahwa kepuasan kerja, prestasi kerja, pergantian pemimpin organisasi, kecerdasan emosional, dan komitmen organisasi merupakan faktor penyebab turnover intention. Menurut hasil penelitian Duraisingam (2009) menyebutkan bahwa job satisfaction dan job stress menjadi penyebab kuat terjadinya turnover intention.

Berdasarkan data dari Perusahaan Bongkar Muat X di Surabaya peningkatan turnover terjadi pada karyawan bagian operasional yang dapat dilihat dalam tiga tahun terakhir yaitu tahun 
2014-2017 yang mengindikasikan adanya peningkatan turnover karyawan bagian operasional. Kepala HRD mengatakan bahwa turnover karyawan bagian operasional 2014 sampai 2017 berada pada kisaran nilai $12-39 \%$ yang artinya masih perlu adanya penanganan. Laporan dari HRD tersebut menunjukkan bahwa terjadi peningkatan turnover karyawan bagian operasional pada Perusahaan Bongkar Muat X di Surabaya.

Berdasarkan latar belakang masalah sebelumnya, dapat diketahui rumusan masalah sebagai berikut. (1) Role Stressor berpengaruh terhadap turnover intention karyawan divisi operasional Perusahaan Bongkar Muat X Surabaya? (2) Apakah Role Stressor berpengaruh terhadap turnover intention karyawan divisi operasional Perusahaan Bongkar Muat X Surabaya melalui job satisfaction? Tujuan penelitian adalah sebagai berikut. (1) Menganalisis pengaruh role stressor terhadap turnover intention karyawan divisi operasional Perusahaan Bongkar Muat X Surabaya. (2) Menganalisis pengaruh role stressor terhadap turnover intention karyawan divisi operasional Perusahaan Bongkar Muat X Surabaya melalui job satisfaction.

\section{KAJIAN TEORI DAN PENGEMBANGAN HIPOTESIS}

\section{Role Stressor}

Stres bisa bersumber dari beberapa faktor atau biasa dikenal sebagai stressor. Menurut Rizzo et al. (1970) dalam penelitian Ozbag et al. (2014) teori mengenai peran (role theory) dinyatakan bahwa ketika perilaku-perilaku yang diharapkan dari seseorang tidak konsisten -merupakan salah bentuk konflik peran- maka dia akan mengalami stres, ketidakpuasan, dan memiliki kinerja yang kurang efektif dibandingkan dengan jika pengharapan yang diinginkan dari perilakunya tersebut tidak mengalami konflik. Robbins \& Judge (2009) dalam pembahasannya mengenai sumber-sumber stres (stressors) antara lain: role conflict, role overload, dan role ambiguity sebagai bagian dari stressor

\section{Job Satisfaction}

Job satisfaction adalah variabel yang paling sering dipelajari dalam penelitian perilaku organisasi dan juga variabel utama dalam penelitian dan teori fenomena organisasi mulai dari desain pekerjaan hingga terkait pengawasan atau pimpinan (Spector, 2000). Lum et al. (1998) turnover intention merupakan variabel yang paling berhubungan dan lebih banyak menjelaskan perilaku turnover itu sendiri dan dapat diketahui dengan tiga komponen penting. (1) Keinginan untuk mencari pekerjaan baru pada bidang yang sama di perusahaan lain. (2) Keinginan untuk mencari pekerjaan baru di bidang yang berbeda di perusahaan lain. (3) Keahlian yang cukup banyak akan mudah membuat seorang individu ingin mencari profesi yang baru yang sebelumnya tidak pernah dia kerjakan.

\section{Turnover Intention}

Bluedorn (1982) dalam Grant et al. (2001) menyatakan turnover intention adalah suatu kecenderungan sikap atau tingkat di mana seorang karyawan memiliki kemungkinan untuk meninggalkan organisasi atau mengundurkan diri secara sukarela dari pekerjaannya. Lum et al. (1998) turnover intention merupakan variabel yang paling berhubungan dan lebih banyak menjelaskan perilaku turnover itu sendiri dan dapat diketahui dengan tiga komponen penting. (1) Keinginan untuk mencari pekerjaan baru pada bidang yang sama di perusahaan lain. (2) Keinginan untuk mencari pekerjaan baru di bidang 
yang berbeda di perusahaan lain. (3) Keahlian yang cukup banyak akan mudah membuat seorang individu ingin mencari profesi yang baru yang sebelumnya tidak pernah dia kerjakan.

\section{Pengaruh Role Stressor terhadap Turnover In- tention}

Salah satu penelitian yang membahas mengenai role stressor yaitu Naidoo (2018) yang menemukan hasil bahwa ada pengaruh positif antara role stressor dan turnover intention. Hal ini menunjukkan bahwa semakin tinggi role stress maka turnover intention juga akan semakin tinggi. Firth et al (2007) mengatakan bahwa role stressor merupakan salah satu faktor penyebab tingginya keinginan karyawan untuk keluar dari pekerjaan.

\section{Pengaruh Role Stressor terhadap Turnover In- tention melalui Job Satisfaction}

Penelitian yang dilakukan oleh Hang-yue (2005) menunjukkan bahwa kepuasan kerja merupakan salah satu variabel yang memediasi antara role stressor dan turnover intention melalui job satisfaction. Hasil dari penelitian tersebut mengatakan bahwa ada pengaruh tidak langsung variabel role stressor dan turnover intention melalui job satisfaction. Dimensi role stressor yang diteliti antara lain role ambiguity, role overload, dan role conflict. Penelitian yang dilakukan oleh Trayambak (2012) mengatakan bahwa role ambiguity, role overload, dan role conflict sangat cocok digunakan dalam variabel role stressor dalam meneliti job satisfaction dan turnover intention.

\section{METODE PENELITIAN}

Penelitian ini menggunakan pendekatan kuantitatif, yaitu pendekatan penelitian yang menitikberatkan pada pengujian hipotesis dengan alat analisis metode statistik dan menghasilkan kesimpulan yang dapat digeneralisasi. Penelitian dengan menggunakan pendekatan kuantitatif menekankan pada data yang terdiri dari angka dan dapat dianalisis menggunakan prosedur statistik. Penelitian ini menggunakan pendekatan penelitian deduktif dengan metode penelitian survei. Penelitian deduktif harus diawali dengan adanya sebuah teori yang sudah ada, kemudian diadakan penelitian untuk membuktikan teori yang sudah ada. Penelitian mengumpulkan informasi dengan cara menyusun daftar pertanyaan atau pernyataan yang diajukan pada responden. Dalam penelitian survei yang dilakukan untuk meneliti perilaku individu, penggalian data dapat dilakukan dengan menggunakan kuesioner dan wawancara (Sujarweni V.W., 2015).

Jenis dan sumber data dalam penelitian ini menggunakan data primer dan data sekunder. Jenis data primer dapat berupa opini subjek (orang) secara individu atau kelompok, hasil observasi terhadap benda (fisik), kejadian, atau kegiatan. Data primer merupakan sumber data penelitian yang diperoleh secara langsung dari sumber asli tanpa melalui perantara pada penelitian ini yaitu jawaban dari karyawan bagian operasional perusahaan bongkar muat X di Surabaya. Data sekunder merupakan sumber data yang diperoleh secara tidak langsung melalui perantara. Data sekunder dalam penelitian ini berupa jurnal, foto dokumentasi lapangan, internet, dan literatur yang berhubungan dengan permasalahan yang diteliti.

Sampel dalam penelitian ini adalah karyawan bagian operasional yang bekerja di Perusahaan Bongkar Muat X Surabaya yang berjumlah 40 orang. Teknik pengambilan sampel yang digunakan adalah teknik sampling jenuh (sensus) di mana semua anggota populasi digunakan sebagai 
sampel (Sujarweni, V.W., 2015). Teknik analisis data penelitian ini menggunakan path analysis.

\section{HASIL DAN PEMBAHASAN}

\section{Hipotesis I}

Hasil penelitian mengemukakan bahwa besarnya tingkat signifikansi diperoleh nilai 0,000 dan nilai ini lebih kecil dari 0,05 . Hasil signifikansi yang diperoleh ini lebih kecil dari 0,05 maka role stressor berpengaruh terhadap turnover intention dan dapat disimpulkan bahwa terdapat pengaruh positif secara langsung dan signifikan. Jika variabel role stressor mengalami perubahan akan berdampak pada perubahan turnover intention. Berdasarkan hasil ini maka dapat dikemukakan bahwa hipotesis I penelitian (H1) sudah dapat terpenuhi.

\section{Hipotesis II}

Hasil penelitian menunjukkan bahwa terdapat pengaruh yang signifikan antara role stressor terhadap turnover intention melalui job satisfaction pada karyawan bagian operasional Perusahaan Bongkar Muat X di Surabaya. Pengaruh tidak langsung role stressor terhadap turnover intention melalui job satisfaction memiliki nilai Beta (â) sebesar 0,595 dengan tingkat signifikan 0,001 . Hasil tingkat signifikansi yang diperoleh lebih kecil dari 0,05 yang menyimpulkan bahwa terdapat pengaruh negatif secara tidak langsung dan signifikan antara role stressor dengan turnover intention melalui job satisfaction. Jika variabel role stressor berubah akan berdampak pada perubahan turnover intention melalui job satisfaction yang artinya saat karyawan bagian operasional Perusahaan Bongkar Muat X di Surabaya yang mengalami stres pekerjaan akibat dari sumber-sumber stres akan berdampak pada menu- runnya job satisfaction dan meningkatnya keinginan untuk keluar dari perusahaan. Hasil dapat dikatakan memediasi sebagian (partial mediation) karena pengaruh dari role stressor terhadap turnover intention baik secara langsung ataupun secara tidak langsung sama-sama masih bersifat signifikan. Hasil dari analisis path dapat digrafikkan sebagai berikut.

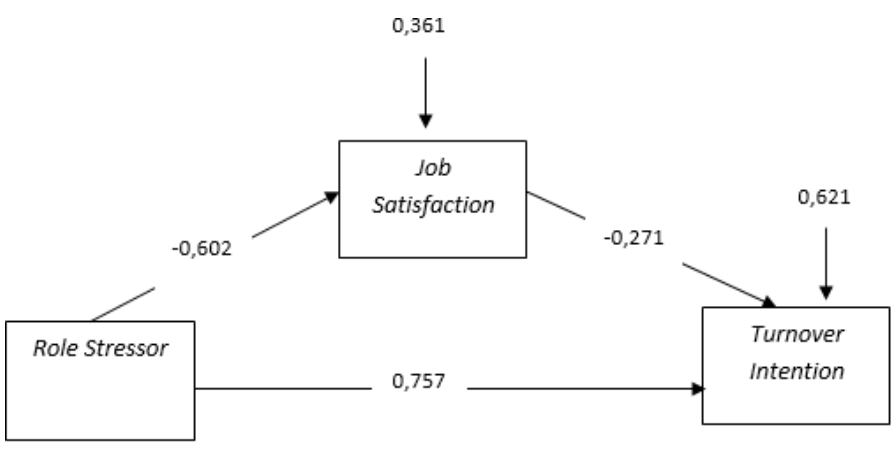

Hasil Penguiian Path Analysis

Nilai $R$-Square pada model regresi pertama menghasilkan nilai sebesar 0,361 menunjukkan bahwa perubahan pada job satisfaction yang dirasakan karyawan bagian operasional Perusahaan Bongkar Muat X di Surabaya dipengaruhi oleh perubahan dalam role stressor sebesar 36\%, sisanya sebesar $64 \%$ dipengaruhi oleh faktor lain. Pada model regresi yang kedua nilai $R$ Square memiliki hasil sebesar 0,621 menunjukkan bahwa perubahan pada turnover intention karyawan bagian operasional Perusahaan Bongkar Muat X di Surabaya dipengaruhi oleh perubahan dari role stressor dan job satisfaction sebesar $62 \%$, sisanya sebesar 28\% dipengaruhi oleh faktor lain. Analisis path dapat dihitung dari nilai $\mathrm{R}$ Square total dengan rumus sebagai berikut.

$$
\begin{aligned}
\mathrm{R}^{2} \text { total } & =1-\left[\left(1-\mathrm{R}_{1}^{2}\right) \times\left(1-\mathrm{R}_{2}^{2}\right)\right] \\
& =1-[0,639 \times 0.379] \\
& =0,757
\end{aligned}
$$

Hasil nilai yang didapat pada $\mathrm{R}$ Square sebesar 0,757 menunjukkan arti bahwa model 
path yang disusun dapat menjelaskan banyak macam kejadian yang terjadi pada variabel role stressor, job satisfaction dan turnover intention sebesar 75,7\%.

\section{Pengaruh Role Stressor terhadap Turnover In- tention}

Hasil penelitian mengemukakan bahwa besarnya tingkat signifikansi diperoleh nilai 0,000 dan nilai ini lebih kecil dari 0,05. Hasil signifikansi yang diperoleh ini lebih kecil dari 0,05 maka role stressor berpengaruh terhadap turnover intention dan dapat disimpulkan bahwa terdapat pengaruh positif secara langsung dan signifikan. Jika variabel role stressor mengalami perubahan akan berdampak pada perubahan turnover intention.

Dalam penelitian ini role stressor terdiri atas tiga dimensi yaitu role ambiguity, role overload, dan role conflict. Jumlah total nilai mean dari variabel role stressor adalah 4,16 dengan item pertanyaan yang memiliki nilai mean terbesar dengan nilai 4,50 yang menjelaskan bahwa karyawan tidak mempunyai rencana dan tujuan yang jelas untuk pekerjaan yang dilakukan. Karyawan merasa tidak mengetahui sasaran tujuan perusahaan dengan jelas sehingga tidak ada feedback mengenai pekerjaan yang sudah diberikan oleh atasan dan dikerjakan sehingga membuat karyawan tidak mempunyai rencana dan tujuan yang jelas dalam bekerja. Karyawan yang tidak dapat bekerja dengan efektif dan terarah dapat menyebabkan meningkatnya keinginan untuk keluar dari perusahaan. Terdapat dua item pertanyaan yang memiliki nilai mean terendah dengan nilai 3,97 yaitu karyawan menerima tugas tanpa tenaga kerja yang membantu untuk menyelesaikannya dan karyawan harus melanggar aturan atau kebijakan untuk melaksanakan suatu tugas. Karyawan dalam bekerja dibebankan untuk se- bisa mungkin mampu menyelesaikan kendalakendala di lapangan saat proses bongkar muat barang tanpa bantuan karyawan lain yang menyebabkan kewalahan dalam menyelesaikan pekerjaan tersebut. Karyawan terkadang harus melanggar aturan atau kebijakan dalam melaksanakan pekerjaan seperti contoh membeli tali tambang atau kayu pallet tanpa persetujuan dari pihak perusahaan agar proses bongkar muat barang tetap berjalan.

Pada persentase usia responden yakni karyawan bagian operasional Perusahaan Bongkar Muat X di Surabaya memiliki usia yang produktif dan matang sebesar 42,5\% karyawan berusia antara 31-40 tahun. Data tersebut dapat ditarik kesimpulan bahwa karyawan bagian operasional Perusahaan Bongkar Muat di Surabaya mampu menghadapi suatu konflik dengan tenang dan tidak terburu-buru. Namun perusahaan tetap harus memperhatikan role stressor karena jika dibiarkan saja dan tidak ditanggulangi maka akan berdampak pada meningkatnya turnover intention karyawan. Hasil Penelitian yang dilakukan oleh Kenneth (2010) mengatakan bahwa role stressor berdampak positif terhadap turnover intention dengan rata-rata tingkat koresponden tinggi terjadi pada karyawan usia 31-40 tahun.

Kesimpulannya adalah perubahan role stressor akan berpengaruh positif dan signifikan terhadap turnover intention pada karyawan bagian operasional Perusahaan Bongkar Muat X di Surabaya.

\section{Pengaruh Role Stressor terhadap Turnover In- tention melalui Job Satisfaction}

Hasil penelitian menunjukkan bahwa terdapat pengaruh yang signifikan antara role stressor terhadap turnover intention melalui job satisfaction pada karyawan bagian operasional Perusa- 
haan Bongkar Muat X di Surabaya. Pengaruh tidak langsung role stressor terhadap turnover intention melalui job satisfaction memiliki nilai Beta (â) sebesar 0,595 dengan tingkat signifikan 0,001 . Hasil tingkat signifikansi yang diperoleh lebih kecil dari 0,05 yang menyimpulkan bahwa terdapat pengaruh negatif secara tidak langsung dan signifikan antara role stressor dengan turnover intention melalui job satisfaction. Jika variabel role stressor berubah akan berdampak pada perubahan turnover intention melalui job satisfaction yang artinya saat karyawan bagian operasional Perusahaan Bongkar Muat X di Surabaya yang mengalami stres pekerjaan akibat dari sumbersumber stres akan berdampak pada menurunnya job satisfaction dan meningkatnya keinginan untuk keluar dari perusahaan. Hal ini konsisten dengan penelitian yang dilakukan oleh Hangyue (2005) serta O'Driscoll dan Beehr (1994) bahwa role stressor berpengaruh terhadap turnover intention melalui job satisfaction. Penelitian yang dilakukan oleh Kenneth (2010) menyatakan bahwa terdapat pengaruh tak langsung variabel role stressor dan turnover intention melalui job satisfaction sehingga disimpulkan perubahan role stressor pada karyawan bagian operasional Perusahaan Bongkar Muat X akan berpengaruh negatif signifikan turnover intention melalui job satisfaction.

\section{KESIMPULAN}

Berdasarkan hasil analisis dari hasil pengolahan data yang telah dilakukan, maka dapat diambil kesimpulan sebagai berikut.

1. Role stressor berpengaruh secara positif dan signifikan terhadap turnover intention pada karyawan bagian operasional Perusahaan Bongkar Muat X di Surabaya, dengan hasil ini maka hipotesis penelitian yang pertama diterima kebenarannya dan dapat dibuktikan secara statistik.

2. Role stressor berpengaruh secara negatif dan signifikan terhadap turnover intention pada karyawan bagian operasional Perusahaan Bongkar Muat X di Surabaya melalui job satisfaction, dengan hasil ini maka hipotesis penelitian kedua diterima kebenarannya dan dapat dibuktikan secara statistik.

\section{SARAN}

Berdasarkan keterangan sebelumnya maka saran yang dapat diberikan dari hasil penelitian ini adalah sebagai berikut.

Berdasarkan hasil deskripsi variabel role stressor ditemukan bahwa nilai rata-rata jawaban responden menunjukkan kategori tidak setuju. Hal ini menunjukkan bahwa karyawan bagian operasional Perusahaan Bongkar Muat X di Surabaya mengalami stress kerja. Hal tersebut dapat berdampak pada kepuasan kerja dan keinginan untuk keluar dari perusahaan karyawan sehingga untuk menanggulangi dan mencegah hal tersebut dapat dilakukan beberapa cara sebagai berikut.

a. Pihak perusahaan harus peduli terhadap pekerjaan karyawannya salah satunya dengan cara mengetahui beban kerja tiap karyawannya. Hal tersebut bertujuan agar karyawan tidak merasa keberatan dengan beban kerja yang diberikan setiap harinya oleh perusahaan.

b. Pihak perusahaan perlu melakukan training and development para karyawan agar karyawan lebih mengerti visi dan misi perusahaan serta mengerti lebih rinci tentang job description masing-masing karyawan. Harapan dari perusahaan agar keinginan karyawan untuk berpindah kerja menurun seiring jelasnya 
standar kerja masing-masing karyawan sesuai job description yang sudah dibuat.

c. Pihak perusahaan perlu mengelola konflik yang terjadi di perusahaan karena jika konflik terjadi secara terus-menerus maka akan berdampak buruk dan menyebabkan penurunan kepuasan kerja dan meningkatnya keinginan untuk keluar perusahaan sehingga perlu koordinasi yang baik antara sesama karyawan maupun atasan dengan bawahan dalam menyelesaikan suatu konflik.

\section{DAFTAR RUJUKAN}

Berry M.L. \& Michael L. Morris. 2008. The Impact of Employee Engagement Factors and Job Satisfaction on Turnover Intent.

Chang, Wan-Jing \& Wang; Yung-Shui \& Huang, Tung. 2013. Work Design-Related Antecedents of turnover intention: A multilevel approach. Human Resource Management.

Duraisingam, V., Pidd, K., \& Roche, M. 2009. The Impact of Work Stress and Job Satisfaction on Turnover Intention: A Studi of Australian Specialist Alcohol and other Drug Workers, 16 (3): 217-231. Retrieved from Taylor \& Francis Online.

Grant Kent, David W. Cravens, George S. Low, \& William C. Moncrief. 2001. "The Role of Satisfaction With Territory Design on the Motivation, Attitudes, and Work Outcomes of Salespeople." Journal of the Academy of Marketing Science, Volume 29, No. 2, P. 165-178.

Hofmann, Verena \& Stokburger-Sauer, Nicola. 2017. The Impact of Emotional Labor on Employees Work Life Balance Perception and Commitment: a Study in the Hospitality Industry. International Journal of Hospitality Management.
Kreitner, Robert \& Kinicki, Angelo. 2003. Perilaku Organisasi. Dalam Early Suandy (Penerjemah). Jakarta: Salemba Empat.

Liu, Y. \& H Tanaka. 2002. Overtime Work, Insufficient Sleep, and Risk of Non-Fatal Acute Myocardial Infarction in Japanese Men. Journal of Occupational and Environmental Medicine, Vol. 59, No. 7, pp. 447-451.

Mobley, W.H., R.W. Graffeth, H.H. Hand, \& B.M. Meglino. 1979. Review and Conceptual Analysis of the Employee Turnover. Journal of Applied Psychology, No. 86, pp 493-522.

Moran John- W. \& Baird K. -Brightman. 2000. Leading Organizational Change Journal of Workplace Learning: Employee Conseling Today, Vol. 12, No.2, pp 66-74.

Naidoo, Rennie. 2018. Role Stress and Turnover Intentions among Information Technology Personnel in South Africa: The Role of Supervisor Support. SA Journal of Human Resource Management, 16, 10. 4102.

Ngo, Hang-Yue \& Foley; Sharon \& Loi, Raymond. 2005. Work Role Stressors and Turnover Intentions: A Study of Professional Clergy in Hong Kong. The International Journal of Human Resource Management, 16.

Pakistan Ram \& Prabhakar. 2013. The Role of Employee Engagement in Work-Related Outcomes. Journal of Research in Business, Vol. 1, No. 3, pp. 47-61.

Ozbag, G.K., Hulya, G.C., \& Gokce, C,C. 2014. Exploring the Effects of Perceived Organizational Impediments and Role Stress on Job Performance. International Strategic Management Conference, Vol. 150, pp. 1129-1136. 
Qureshi, Muhammad Imran \& Mehwish Iftikhar. 2013. "Relationship between Job Stress, Workload, Environment and Employees Turnover Intentions: What We Know, What Should We Know". World Applied Sciences, Volume 23, No. 6, Hal. 764770.

Robbins, S.P. 2009. Perilaku Organisasi: Konsep, Kontroversi, Aplikasi, Edisi Keenam, Terjemahan. Jakarta: Prehalindo.

Robert L. Mathis \& John H. Jackson. 2006. Human Resource Management, Edisi 10. Jakarta: Salemba Empat.

Saeed, I., Waseem, M., Sikander, S., \& Rizwan, M. 2014. The Relationship of Turnover Intention with Job Satisfaction, Job Performance, Leader member Exchange,
Emotional Intelligence and Organizational Commitment. International Journal of Learning and Development, 4(2), pp. 24256.

Spector, P.E. 2000. Industrial and Organizational Psychology Research and Practice, Second Edition. New York: Jhon Wily \& Sons, Inc.

Sujarweni, V. Wiratna. 2015. Statistik untuk Bisnis dan Ekonomi. Yogyakarta: Pustaka Baru Press.

Trayambak, Mrs. 2012. A Conceptual Study on Role Stressors, Their Impact and Strategies to Manage Role Stressors. IOSR Journal of Business and Management, 4, 4448. 10.9790/487X-0414448. 